\title{
Pesquisa e mudança social: desafios e dificuldades para a formação em Psicologia
}

\section{Research \& change social: challenges and difficulties to training in the Psychology}

\author{
Raquel Souza Lobo Guzzo*
}

\begin{abstract}
RESUMO
A proposta deste artigo é apresentar dificuldades e desafios enfrentados na formação de pesquisadores para a área da Psicologia no Brasil. O sentido da pesquisa que muda a realidade, requisitos de estudantes de pós-graduação e a relação graduação pós-graduação nessa formação. A conjuntura brasileira e a pesquisa como uma possibilidade de crítica e mudança social. As dificuldades econômicas e políticas para uma pesquisa socialmente comprometida. Palavras-chave: Formação. Pesquisa. Psicologia Crítica.
\end{abstract}

\begin{abstract}
The purpose of this article is to present difficulties and challenges faced in the training of researchers in the field of Psychology in Brazil. The sense of research that changes reality, graduate student requirements and the postgraduate graduation relationship in that training. The Brazilian conjuncture and the research as a possibility of criticism and social change. The economic and political difficulties for a socially committed research.
\end{abstract}

Keywords: Training. Research. Critical Psychology.

* Pontifícia Universidade Católica de Campinas. Programa de Pós-Graduação em Psicologia. Campinas, São Paulo, Brasil. E-mail: rslguzzo@gmail.com. https://orcid.org/0000-0002-7029-2913. 


\section{Introdução - A importância da pesquisa e da produção do conhecimento}

A ciência é responsável pelo conhecimento elaborado com finalidade própria, no tempo e espaço em que é realizada. Há uma considerável discussão em torno das razões para a geração do conhecimento. Mas uma questão é certa - a produção do conhecimento é uma elaboração humana e, por isso, não é despida de interesses, portanto, é política. Na história da produção do conhecimento, sempre houve uma estreita relação entre o produto da ciência e a vida em sua amplitude máxima. A ciência serve ao propósito de entender, de preservar a vida e, mais do que isso, de descobrir formas de mudá-la. Desde a cura de doenças, passando por distintas formas de enfrentar cotidianos adversos, a ciência sempre abre a possibilidade da transformação social.

Não se pode negar o impacto das políticas econômicas na Educação em geral sobre tudo na formação de pesquisadores.

O capitalismo transformou a vida cotidiana em mera luta pela riqueza. Os indivíduos passaram a considerar todos os outros como adversários, e a sociedade se converteu na arena em que essa luta se desenvolve. As relações econômicas de mercado são expressões nítidas dessa nova relação entre os indivíduos e a totalidade social. Todos são inimigos de todos, 'o homem é o lobo do homem', no dizer do filósofo Thomas Hobbes. (1588-1679) (LESSA; TONET, 2011, p. 79).

Compreender o capitalismo como o elemento fundamental para o estabelecimento de tal forma conflituosa de relações entre os indivíduos em sociedade faz parte da concepção que Lessa e Tonet (2011) atribuem às relações sociais, pautados nos pensamentos de Marx e Engels. Na mesma obra citada anteriormente, iniciam uma discussão acerca da superação dessa truculenta condição em que se encontram as relações entre os homens, apresentando dois pontos de vista opostos. O primeiro, mais conservador, admite ser impossível tal superação, pelo fato de o individualismo e a exploração constituírem parte da essência humana. Nessa perspectiva conservadora, a democracia e o mercado presentes no sistema capitalista seriam a forma mais civilizada de lidar com tal essência. A perspectiva oposta a esta é a revolucionária, representada pelas ideias de Marx, para quem não só é possível como é também necessária a superação dessa exploração por meio de processos emancipatórios, considerando que a sociedade como está tem evoluído para a barbárie e não para formas mais civilizadas de exploração. 
Atualmente, o neoliberalismo econômico tem sido o mecanismo que qualifica o mercado como a única instituição capaz de coordenar racionalmente os problemas econômicos e políticos (TEIXEIRA, 1996), em acordo com a postura conservadora explicitada anteriormente. Como sistema econômico, o neoliberalismo surgiu logo em seguida à Segunda Guerra Mundial, como uma reação teórica e política ao modelo de desenvolvimento centrado na intervenção do Estado (TEIXEIRA, 1996). Neste contexto, a teoria neoliberal é tomada como a solução para os problemas da humanidade em escala mundial e, ainda, segundo esse autor, "um credo mundial que deve ser abraçado por qualquer país" (TEIXEIRA, 1996, p. 195). Isso significa que a disseminação do novo mecanismo por todo o mundo coloca então o mercado em uma posição insuperável e articulador indispensável também para a solução dos problemas sociais.

Em acordo com as transformações do período pós-segunda guerra, destaca-se o nascimento das duas organizações internacionais de articulação econômica: o Banco Internacional de Reconstrução e Desenvolvimento - BIRD, também conhecido como Banco Mundial; e o Fundo Monetário Internacional - FMI, ambos criados na Conferência de Bretton Woods, em 1944, nos Estados Unidos, e nomeados como organismos especializados da ONU em 1947. Segundo Sguissardi (2000), ambas atuaram ao longo da segunda metade do século XX em países de terceiro mundo, articulando as relações econômicas entre estas nações com os ajustes estruturais necessários à globalização econômica. Apesar de seu nascimento, ainda ao final da primeira metade do século XX, foi ao final da segunda metade desse século, que tais organismos intensificaram suas ações nos países em desenvolvimento, contribuindo com

os esforços de concepção e ação para garantir os profundos ajustes impostos pelo ideário neoliberal e, então, sumarizados, pelo Consenso de Washington: busca de equilíbrio orçamentário, abertura comercial, liberalização financeira, desregulamentação do mercado interno e das relações de trabalho, redução dos gastos públicos e privatização de empresas e serviços estatais ou públicos. (SGUISSARDI, 2000, p. 4).

No Brasil, ambas as agências atuaram unidas com uma representatividade crescente a partir da década de 1970 nos setores da saúde e da educação (FONSECA, 1998). Porém, como agência financiadora, o Banco Mundial passou a exigir acordos políticos para o investimento nos países credores. Um desses acordos foi o desinvestimento do Estado na Educação Superior, pela justificativa de que o investimento na educação fundamental e no ensino técnico deveria 
tornar-se prioridade por serem estes a solução para a superação da pobreza. Ao Ensino Superior, então, recomendou a "flexibilidade e diferenciação entre as instituições", incentivando o progresso das instituições privadas de ensino (CALDERÓN; FRANÇA, 2013).

Isso significou o investimento na privatização dos setores públicos, na expectativa de reforçar "o deslocamento do público para o individual, sob o controle 'natural' das leis do mercado" (FONSECA, 1998, p. 5). Dessa forma, os indivíduos, por seus méritos, superariam a pobreza do país e os ideais de abertura comercial seriam gradualmente difundidos.

Calderón e França (2013, p. 103) realizaram um levantamento bibliográfico de artigos publicados na década de 1980, buscando os que fossem relacionados ao tema da "autonomia universitária, como resposta ao intervencionismo exógeno na definição das políticas da educação superior na década de 1980”. Ao longo do estudo, observa-se que, por intervencionismo exógeno, os autores entendem a ação do Banco Mundial como um dos principais organismos que assumiram a intervenção nos processos educacionais do país, preparando o terreno da educação para o encravamento da bandeira do neoliberalismo. Citam em seu trabalho Leher (1999 citado por CALDERÓN; FRANÇA, 2013), para aprofundar sobre as ações do Banco Mundial nos países de terceiro mundo, categoria na qual o Brasil se encaixava. Para Leher, a ação do Banco Mundial de atender aos países periféricos visava combater a ideologia comunista, mediante investimentos em escolas técnicas, programas de saúde e controle de natalidade.

Ao mesmo tempo, o Banco orientou os países emergentes a adotarem maior flexibilidade e diferenciação entre as Instituições de Ensino Superior, estimulando o surgimento de instituições com financiamento privado, sem compromisso com a pesquisa, vocacionada para o ensino de massas. Ao fazê-lo, o Banco recomendou também que o Estado restringisse as formas de financiamento à educação superior e criasse instrumentos permitindo a exploração dessa atividade às instituições privadas (CALDERÓN; FRANÇA, 2013, p. 104).

Percebe-se então, que o setor da Educação tornou-se alvo do planejamento racional de recursos públicos, a fim de que fossem as Instituições de Ensino Superior [IES] integradas no processo de privatização da educação ao ponto de, no ano de 1980, em um total de 882 IES no país, 682 (77\%) pertenciam ao setor privado, enquanto apenas 200 pertenciam à administração pública. Trinta anos depois, no ano de 2012, observou-se esta mesma dinâmica crescendo ainda 
mais. Em um total de 2.416 instituições, 2.112 eram privadas, o que representa $87 \%$ das IES brasileiras, enquanto apenas 304 eram públicas (INEP, Sinopse da Educação Superior, 2012).

Diversas reuniões aconteceram ao longo da década de 1990, justamente pela dificuldade de se encontrar um acordo entre os interesses da Organização Mundial do Comércio - OMC, dos governos e das Instituições de Ensino Superior, segundo Dias (2003). Enfim, em 2002 na cidade de Washington, EUA, reuniram-se membros da Organização de Cooperação e Desenvolvimento Econômico - OCDE, do Banco Mundial, do Serviço de Comércio, do Departamento de Estado do governo norte-americano e diversas outras entidades, além do Ministro da Educação do Brasil, Paulo Renato de Souza, com o objetivo de "revigorar a interpretação de que, segundo as normas já aprovadas pelos diversos países desde 1994, todos os serviços devem submeter-se às regras e aos controles elaborados no quadro da OMC" (DIAS, 2003, p. 822). Desde então, organizações universitárias e grupos representantes de universidades se manifestaram contra a decisão, em uma tentativa de mobilizar a comunidade acadêmica para a seriedade da questão, também no Brasil.

Além de Dias (2003), Calderón e França (2013) também identificaram o movimento de privatização do Ensino Superior como um "abandono de uma política nacional verdadeiramente soberana e que enfatize a educação como bem público" (CALDERÓN; FRANÇA, 2013, p. 105), para submeter-se à disseminação imposta do neoliberalismo.

\section{A pesquisa no Brasil - cenário na produção e relação com a realidade}

A Psicologia como ciência produz um campo de conhecimento importante para a compreensão do desenvolvimento humano em distintos contextos sociais, pela análise das experiências cotidianas e o impacto de algumas situações concretas nos processos de saúde e doença. Por esse motivo, a Psicologia tem relevância, sobretudo, porque fornece subsídios para uma discussão sobre ética e vida social dentre outras contribuições teóricas em diálogo com outros campos do saber. Apesar disso, nem todo conhecimento psicológico sustenta uma prática emancipadora. Pelo contrário, a grande parte do conhecimento produzido pela ciência psicológica tem se constituído em uma argamassa para a constituição de um modo de vida incompatível com a humanização, por excelência, das relações sociais. 
Quando os fundamentos de uma ciência e as práticas decorrentes não impactam a vida cotidiana da maioria das pessoas, no sentido de produzir mudanças nas perspectivas de futuro, na saúde física e psicológica e no pleno desenvolvimento das crianças e jovens, significa que não servem ao horizonte emancipador e se apresentam submissas a outros interesses, esvaziando de sentido a busca por uma vida digna. É obvio que existem vários sentidos e contextos para a produção do conhecimento, mas é sempre importante a análise do que tem sido produzido com recursos públicos e o avanço real que esse conhecimento tem propiciado.

Nessa perspectiva, e considerando que a Pesquisa em Psicologia pertencendo à área do conhecimento das Ciências Humanas e Sociais, os investimentos feitos na formação de pesquisadores e no avanço do conhecimento já justificariam uma avaliação do impacto dessa produção sobre a vida da maioria das pessoas provenientes das camadas populares, que lutam por direitos básicos para viver com dignidade. A Psicologia tem uma trajetória histórica em que predomina a condição de uma ciência liberal comprometida com o ajustamento pessoas à condição da conjuntura social e econômica (PARKER, 2007). No Brasil, foi regulamentada como profissão em 1962 e se consolidou no período da ditadura civil-militar com imenso impacto na formação básica de estudantes e futuros profissionais. Até os dias de hoje, nem a formação nem o exercício profissional não conseguem se desligar dessa carga tecnicista que pouco responde às demandas do serviço público no atendimento às camadas populares. Professores e pesquisadores ainda reproduzem o modelo hegemônico em que foram formados e são responsáveis por uma enorme quantidade de estudantes que não fazem uma leitura crítica da Psicologia e a mantém como uma poderosa ferramenta a serviço da atual forma de sociabilidade que causa sofrimento na maioria das pessoas. Apenas para destacar um elemento: durante os primeiros vinte anos de formação dos Psicólogos no Brasil a predominância do perfil profissional era de um psicólogo clínico, cuja prática profissional era voltada à população que podia pagar pelos atendimentos em consultórios privados e fundamentada em um modelo médico-positivista com intervenções terapêuticas remediativas. Refletindo as marcas do processo de colonização vivido pelos países do continente americano, a Psicologia, como uma profissão recente, acabou por se desenvolver no Brasil e outros países da América Latina, predominantemente, por um mimetismo científico (MARTÍN-BARÓ, 1998), ou seja, uma importação acrítica dos conhecimentos produzidos nos países do hemisfério norte, predominantemente dos Estados Unidos. 


\section{A formação para a pesquisa e a formação com pesquisa - o caso da Psicologia}

Diante das políticas para a formação de profissionais da Psicologia no Brasil, uma análise de documentos oficiais produzidos para o Ensino Superior no Brasil, mais especificamente, as Diretrizes Curriculares Nacionais para os cursos de Psicologia, instituídas em 2004, fica evidente a constatação de contradições presentes no documento e em sua aplicação nos cursos. Também, observou-se que há poucas discussões sobre a formação, se comparado à discussão sobre áreas mais específicas e tradicionais da atuação do psicólogo.

Apesar de as instituições de formação em Psicologia já estarem em expansão no Brasil desde a regulamentação da profissão no ano de 1962, com a promulgação da Lei $\mathrm{n}^{\circ} 4.119$ (MANCEBO, 1999), na década de 1990 havia ainda discussões sem consenso sobre tal formação no país.

Duran (1994) apresentou o problema colocando a preocupação com a formação como uma questão muito presente ainda no meio acadêmico não só da Psicologia, mas para a formação superior brasileira de uma forma geral:

Essa não é uma realidade apenas da Psicologia e nem apenas brasileira. As mudanças rápidas, de natureza variada, que ocorrem especialmente no Primeiro Mundo, com desdobramentos para os demais, criam um descompasso entre a educação e as condições decorrentes dessas mudanças. Modificações de currículo seriam o caminho para dar conta dessas transformações. (JORGE, 1993 citado por DURAN, 1994).

Em meio às mudanças que ocorrem nos países desenvolvidos, destaca-se o desenvolvimento econômico, contextualizado na seção anterior, do qual dependem a ciência e tecnologia desenvolvidas nas universidades também dos países em desenvolvimento (GEORGEN, 2008). Para o autor, "no limite, a própria educação passa a ser considerada um mero serviço, cujos direitos podem ser arrebatados nos pregões das bolsas por qualquer instituição de qualquer parte do mundo" (GEORGEN, 2008, p. 8).

A diversificação do ensino superior e dos cursos, com a inserção de cursos a distância, modalidades diversas de duração, ensino técnico, etc.; e a diversificação das fontes de financiamento das universidades públicas, com estratégias apresentadas pelo BM para a reforma da educação superior na América Latina, Ásia e Caribe (LIMA, 2011), de fato trouxeram reflexos para a formação em 
Psicologia no Brasil. Entre os anos de 1997 e 2012, o número de formados nos cursos de Psicologia no país avançou de 10.208, para 19.596: um aumento expressivo de $192 \%$ em um período de 15 anos. Destes 19.596 formados em $2012,16.077$ (82\%) vieram de instituições privadas, enquanto que apenas 3.519 formaram-se em instituições públicas (INEP, 2012).

A rápida proliferação dos cursos superiores de Psicologia no país foi razão de preocupações como a de Calais e Pacheco (2001) e mais tarde de Lisboa e Barbosa (2009), de que tal alastramento, ocorrendo sem o acompanhamento da qualidade, deveria ser visto como um "descompasso entre o profissional que temos e o que queremos formar" (CALAIS; PACHECO, 2001, p. 12).

Em meio ao contexto econômico e político no qual a Educação Superior se desenvolveu na década de 1990, algumas oposições da formação em Psicologia começaram a ser discutidas, como os dilemas entre formar psicólogos generalistas ou especialistas; entre um currículo rígido ou flexível; entre cursos teóricos ou essencialmente práticos; além dos dilemas éticos referentes à formação (DURAN, 1994). Para a autora, mudanças curriculares deveriam ser consideradas para atingir as demandas da educação; no entanto, com algumas ressalvas sobre o uso e alterações de sua estrutura, pois afirma que o currículo, "na maior parte das vezes é usado no que diz respeito às estruturas normatizadoras do processo de formação", sendo que, na história da formação em Psicologia, "tem se abusado dele como panaceia de todos os problemas" (DURAN, 1994, p. 307).

Em seu trabalho em parceria com o Conselho Federal de Psicologia à época, Duran (1994, p. 275) realizou um levantamento de posicionamentos de diversos profissionais da área de ensino da Psicologia, a fim de constituir um "conjunto de posicionamentos sobre questões relevantes da formação que tem permanecido como pontos de entrave em processos de revisão curricular". Em seus resultados, as necessidades que mais se destacaram foram: o direcionamento de uma formação para a realidade de nosso país, a união de uma formação teórica com a prática e a multidisciplinaridade (DURAN, 1994). Semelhantemente, Guzzo (2011) afirma que o comprometimento com a realidade brasileira deveria se estabelecer por meio de uma formação politizada e crítica, para a libertação da formação hegemônica que se faz presente na grande maioria das universidades do país.

No início dos anos 1990, a elaboração das Diretrizes Curriculares Nacionais para os cursos de graduação em Psicologia [DCN] já estava sob os cuidados do Ministério de Educação e Cultura (MEC), por meio da nomeação de comissões de especialistas (HOFF, 1999). No entanto, os desacordos entre os documentos de propostas da comissão e aqueles advindos dos setores organizados de entidades polarizavam-se em dois grupos opostos. O primeiro grupo, representado pela comissão, previa uma formação tecnicista, voltada para as 
especificidades, enquanto que o segundo grupo, dos representantes das entidades, defendia uma formação mais generalista, com ênfase na prevenção e promoção de saúde. A autora, que se inseriu na discussão em um período de grande profusão de divergentes opiniões, nos anos de 1998 e 1999, teve por finalidade cooperar com a proposta das diretrizes questionando dois temas: que tipo de psicólogos as diretrizes curriculares pretendiam formar e se as DCN contemplariam os princípios de formação e o perfil de profissional, defendidos nos Congressos Nacionais de Psicologia (HOFF, 1999). Percebe-se que o questionamento de Hoff centra-se em quais interesses estariam por trás da elaboração das DCN, e se as propostas das entidades seriam levadas em consideração em sua elaboração.

A primeira comissão de especialistas, nomeada pelo MEC em 1995, sugeriu estruturalmente uma formação básica e pluralista sólida, possibilitando a integração de conteúdos para uma formação generalista; uma formação interdisciplinar, dialogando com outras áreas do conhecimento; a preparação para uma atuação multiprofissional; a garantia de uma formação científica, crítica e reflexiva; a efetiva integração teoria-prática por intermédio de um processo de observação da realidade concreta, seguida da investigação e, por fim, da intervenção; o compromisso com o atendimento das demandas sociais, valorizadas nas disciplinas, estágios e preferência pela bibliografia nacional; o compromisso ético permeando todo o currículo; o rompimento com o modelo de atuação tecnicista, pela intervenção estratégica e política não individualizada, ou descolada do contexto histórico; e a necessidade de precisar as terminalidades dos cursos de Psicologia, (BORGES; BASTOS; KHOURY, 1994).

As dez diretrizes propostas por essa primeira comissão foram coerentes com as discussões realizadas até então nos eventos e em pesquisas das entidades, assim como em Instituições Acadêmicas e Profissionais da Psicologia (BUETTNER, 2000). Se fosse o documento da comissão levado à frente, despolarizaria os grupos e opiniões citados anteriormente, no entanto, a composição da comissão foi alterada, assim como suas propostas.

A partir de então, instalou-se um campo de batalha entre os interesses das comissões e as entidades até que, no ano de 2004, Conselho Nacional de Educação (CNE/CNS, Parecer $n^{\circ}$ 062, de 19 de fevereiro de 2004) manifestou-se esclarecendo que, das discussões que se decorreram desde o ano de 1999, dois principais grupos se manifestaram, arranjados de acordo com suas opiniões opostas. O primeiro deles aprovava a disponibilidade da formação do psicólogo em diferentes perfis. O curso de Bacharelado, uma formação de preparo para a pesquisa; Licenciatura, com a finalidade de formar professores; e a Formação do Psicólogo, voltada para a formação do profissional. Todas as instituições ofereceriam obrigatoriamente o terceiro perfil, cabendo a elas decidir se optariam por oferecer as duas primeiras opções, de acordo com suas adequações. 
O segundo grupo discordava dessas condições, defendendo um perfil único de formação "abrangente e pluralista". Diante de tais divergências, a comissão sugeriu que os dois grupos elaborassem um documento em comum, superando os desacordos, e no parecer aqui citado, apresenta as novas Diretrizes Curriculares, em um formato amplo, advindo de diferentes sugestões e de superações de discordâncias. Define os eixos estruturantes aos quais os cursos devem compor sua formação, com base em um núcleo comum, constituído de competências básicas, que garantem a identidade dos cursos de Psicologia no país.

Alguns meses depois, em maio de 2004, o Conselho Nacional de Educação, por sua Comissão de Ensino Superior (CNE/CES) instituiu as Diretrizes Curriculares para os cursos de graduação em Psicologia (CNE/CNS, Resolução $\mathrm{n}^{\mathrm{o}} 8$, de 7 de maio de 2004), versão que foi atualizada no ano de 2011 com o estabelecimento de normas para o projeto pedagógico complementar para a Formação de Professores de Psicologia (CNE/CES, Resolução n ${ }^{\circ}$ 5, de 15 de março de 2011).

A história aqui contada sobre a formação em Psicologia no Brasil expõe momentos nos quais a discussão sobre a formação no país mostrou-se determinante na busca de soluções para os impasses vigentes, como aconteceu às vésperas da elaboração das Diretrizes e sua instituição em 2004.

\section{Dificuldades na formação e enfrentamentos necessários}

As dificuldades na formação esbarram sempre nos interesses institucionais, os quais, por sua vez, no caso da Psicologia, estão voltados, em sua maioria aos interesses do mercado. Diante disso, considera-se como uma das maiores dificuldades na formação que a mesma se oriente pela prática social, critério da verdade do método assumido, ou seja, vale-se daquilo que é realizado na prática e não apenas na teoria, afinal, para Marx (1845/1982, p. 2), “A questão de saber se ao pensamento humano pertence à verdade objetiva não é uma questão de teoria, mas uma questão prática".

Em um estudo sobre as políticas educacionais e a formação em Psicologia (OLIVEIRA; PINHO; GUZZO, 2014) foram encontrados 680 artigos, obedecendo ao critério de publicação, a partir de 2004, ano da instituição das Diretrizes Curriculares Nacionais para os cursos de graduação em Psicologia. Foram analisados nos artigos estudados, as críticas a respeito da aplicação das diretrizes curriculares, e até mesmo críticas a respeito de sua elaboração. O tema 
das contradições, entre uma formação generalista versus especialista, ainda aparece mesmo depois da institucionalização das Diretrizes. Isso demonstrou o descontentamento por parte dos profissionais com relação à formação, ainda sem consenso nos dias atuais. A análise de seus resultados permitiu a observação de que "a produção sobre a temática se encontra dispersa e possui caráter opinativo; grande parcela das publicações focaliza áreas tradicionais da Psicologia e aborda o tema por uma ótica internalista." (COSTA et al., 2012, p.135).

\section{Desafios e horizontes}

Em uma reflexão, com base na proposta das Diretrizes Curriculares, Moura (1999) afirmou que

Este deve ser o ponto de partida da longa e árdua caminhada que temos a percorrer: tomarmos consciência daquilo que não mais queremos, daquilo que não mais podemos fazer. É bem verdade que já temos uma referência sobre o que precisamos e queremos fazer: construir um profissional capaz de empreender uma prática pluralista, crítica e transformadora, que saiba reconhecer as demandas de intervenção e propor caminhos que atendam à essas demandas. (MOURA, 1999, p. 19).

A opinião de Moura (1999) foi uma entre tantas outras expressas por entidades de profissionais e acadêmicos naquele período, poucos anos antes da instituição do documento. No entanto, assim que as DCN foram instituídas, as discussões acerca da formação não parecem ter acompanhado o ritmo de luta daqueles que defendiam uma transformação na formação, como Moura (1999). A pequena parcela de artigos que tratam centralmente sobre o tema da formação, adiante da representativa maioria das publicações em áreas específicas, representa a realidade na qual se encontram as IES formadoras de psicólogos em nosso país. Uma formação voltada para os interesses do mercado, ainda aliada ao capitalismo, concordando com Mancebo (1999 citado por PALMA; MORAES, 2012, p. 637), de que seu "veículo principal foram as especialidades psi, responsáveis pela psicologização das demandas sociais e políticas". 


\section{Considerações finais}

Podemos apontar que, da maneira como está entrelaçada a formação em Psicologia no Brasil aos padrões neoliberais estabelecidos nas políticas educacionais para o Ensino Superior, será difícil uma virada na formação profissional e científica para a transformação social. Essa é uma trama composta de acordos políticos, motivações econômicas e interesses de grupos dominantes. A instituição das Diretrizes Curriculares para os cursos de Psicologia no ano de 2004 parece ter dividido em dois períodos a movimentação dos profissionais na discussão sobre a formação. Na década que o antecedeu, muito se debateu para que as DCN cumprissem a promessa de transformar a formação no país e, por conseguinte, o perfil profissional e o conhecimento científico para o enfrentamento das questões sociais presentes na realidade brasileira. Na década que se seguiu à instituição do documento, pouco se falou sobre impacto das DCN e quem e como estariam sendo formados os profissionais da Psicologia, e nem como e para quem o conhecimento produzido estava servindo. A questão parece continuar ecoando: como se espera mudanças na formação em Psicologia, se há tão pouca discussão sobre ela?

\section{REFERÊNCIAS}

BORGES, M.; BASTOS, A.; KHOURY, Y. A formação em Psicologia: contribuições para a reestruturação curricular e a avaliação dos cursos. Brasília: MEC-SESu, 1994.

BUETTNER, G. E. Diretrizes Curriculares em Psicologia: discursos de resistência. Campinas: Instituto de Psicologia e Fonoaudiologia da Pontifícia Universidade Católica de Campinas, 2000.

CALAIS, S.; PACHECO, E. Formação de psicólogos: análise curricular. Psicologia Escolar e Educacional, v. 5, n. 1, p.11-18, 2001.

CALDERÓN, A.; FRANÇA, C. O Banco Mundial na educação superior brasileira: de ilustre desconhecido nos anos 1980 a protagonista nos anos 1990. Universidade e Sociedade, Andes-SN, ano XXII, n. 52, p. 102-115, 2013.

CNE/CES. Resolução $n^{\circ} 5$, de 15 de março de 2011. Institui as Diretrizes Curriculares Nacionais para os cursos de graduação em Psicologia, estabelecendo normas para o projeto pedagógico complementar para a Formação de Professores de Psicologia. Brasília, 16 de março de 2011. 
CNE/CNS. Parecer $n^{\circ}$ 062, de 19 de fevereiro de 2004. Parecer que aprova as Diretrizes Curriculares de Psicologia. Brasília, 2004.

CNE/CNS. Resolução $n^{\circ}$ 8, de 7 de maio de 2004. Institui as Diretrizes Curriculares para os cursos de graduação em Psicologia. Brasília, 2004.

COSTA, J. P.; COSTA, A. L.; LIMA, F. C.; SEIXAS, P. D.; PESSANHA, V. C.; YAMAMOTO, O. H. A produção científica sobre a formação de Psicólogos no Brasil. Psicologia em Pesquisa, v. 6, n. 2, p. 130-138, dez 2012.

DIAS, M. Comercialização no Ensino Superior: é possível manter a ideia de bem público? Educação e Sociedade, v. 24, n. 84, p. 817-838, 2003.

DURAN, A. Alguns dilemas na formação do psicólogo: buscando sugestões para superá-los. In: C. F. PSICOLOGIA. Práticas emergentes e desafios para a formação. São Paulo: Casa do Psicólogo, p. 273-308, 1994.

FONSECA, M. O Banco Mundial como referência para a justiça social no Terceiro Mundo: evidências do caso brasileiro. Revista da Faculdade de Educação, v. 24, n. 1, p. 37-69, 1998.

GEORGEN, P. Educação Superior e responsabilidade social: do discurso à ação. Tendencias de la educación superior en América y el Caribe. Contribución a los documentos sinteis, 2008.

GUZZO, R. Desafios cotidianos em contextos educativos: a difícil formação de psicólogos para a realidade brasileira. In: AZZI, R. G.; GIANFALDONI, M. H. T. A. Psicologia e Educação. São Paulo: Casa do Psicólogo, p. 253-270, 2011.

HOFF, M. S. A proposta de diretrizes curriculares para os cursos de psicologia: uma perspectiva de avanços? Psicologia, Ciência e Profissão, v. 19, n. 3, p. 12-31, 1999.

INEP. Sinopse da Educação Superior. Brasília: Ministério da da Educação e da Cultura, 2012.

LESSA, S.; TONET, I. Introdução à Filosofia de Marx. São Paulo: Expressão Popular, 2011.

LIMA, K. O Banco Mundial e a educação superior brasileira na primeira década do novo século. Rev. Katálysis (online), v. 14, n. 1, p. 86-94, 2011.

LISBOA, F. S.; BARBOSA, A. J. Formação em Psicologia no Brasil: um perfil dos cursos de graduação. Psicologia: Ciência e Profissão (online), v. 29, n. 4, p. 718-737, 2009.

MANCEBO, D. Formação em Psicologia: gênese e primeiros desenvolvimentos. In: JACÓ-VILELA, A. M. et al. (Org.). Clio-Psyché - Histórias da Psicologia no Brasil. Rio de Janeiro: NAPE/UERJ, 1999.

MARTÍN-BARÓ, I. Psicología de la Liberación. Madrid, Espanha: Editorial Trotta, 1998.

MARX, K. Teses sobre Feuerbach. Avante, 1845/1982. 
MOURA, E. P. A Psicologia (e os psicólogos) que temos e a Psicologia que queremos. Psicologia: Ciência e Profissão, v. 19, n. 3, p. 10-19, 1999.

OLIVEIRA, P. S.; PINHO, C.; GUZZO, R. S. L. A formação do Psicólogo no Brasil: compromissos com a realidade? Relatório não publicado de Iniciação Científica. Campinas: PUC-Campinas, 2014.

PALMA, N. S.; MORAES, M. Psicólogos em forma[ta]ção: cartografias de um esboço de autoanálise. Estudos e Pesquisas em Psicologia, v. 12, n. 2, p. 623-647, 2012.

PARKER, I. Revolution in Psychology: Alienation to Emancipation. London: Pluto Press, 2007.

SGUISSARDI, V. O Banco Mundial e a educação superior: revisando teses e posições? Universidade e Sociedade, v. 10, n. 22, p. 66-77, 2000.

TEIXEIRA, F. J. O neoliberalismo em debate. In: TEIXEIRA, F. J.; OLIVEIRA, M. Neoliberalismo e reestruturação produtiva: as novas determinações do mundo do trabalho. São Paulo: Cortez, p. 195-252, 1996.

Texto recebido em 17 de maio de 2018. Texto aprovado em 17 de julho de 2018. 